\title{
ЦЕЛЕВОЕ УПРАВЛЕНИЕ ТРУДОВЫМИ РЕСУРСАМИ: ЗАДАЧИ, ПРОГРАММНО-ИНФОРМАЦИОННОЕ ОБЕСПЕЧЕНИЕ
}

\author{
(c) 2020 Волков Денис Владимирович \\ управляющий директор $\mathrm{OOO}$ «А-Л»
}

Рассмотрены возможности использования цифровых технологий в целях управления трудовыми ресурсами. Делается вывод, что эффективность управления определяется демографической политикой и уровнем (индексом) развития человеческого потенциала (ИРЧП), а также применением когнитивных и облачных технологий, Интернета вещей и промышленного Интернета, Больших Данных (Big Data). Утверждается, что дирижерские (управленческие) функции в этом случае должно взять на себя государство в постоянном взаимодействии с организациями, деятельность которых связана с информационно-компьютерными технологиями (ИКТ). Современное управление трудовыми ресурсами усиливает потребность в профессиональных, стратегически мыслящих и инновационно ориентированных специалистах, обучение и воспитание которых невозможно без серьезного совершенствования образовательной системы РФ.

Ключевые слова: Трудовые ресурсы, управление, баланс трудовых ресурсов, цифровые технологии, когнитивные и облачные технологии, Больщие данные (Big Data).

Управление трудовыми ресурсами на основе использования современных средств вычислительной техники и информатики - приоритетный ресурс экономического развития России. Как известно, еще в Советском Союзе (60-е - 70-е годы прошлого столетия) конструирование и производство ЭВМ на отечественных интегральных схемах полупроводников стало многоплановым проектом. Последовательно создавались АСУ, АСТП, АСУ с ЧПУ, ОАСУ. Закрытый проект, названный АСУ (А+9+1000), включал в себя следующие системы: «Алмаз Госплана СССР», АСУ девяти министерств ВПК и тысячи взаимодействующих предприятий, НИИ, КБ и организаций оборонной сферы. В рамках этого проекта были запущены функционирующие в реальном времени:

- АСУ - цех (автоматизированные системы управления цехами и другими подразделениями предприятий ВПК);

- АСУ главного производственного управления;

- АРМ (автоматизированные рабочие места специалистов) [1].

Тогда же специальным решением Госплана СССР был создан государственный фонд алгоритмов и программ, а также выдвинута концепция «управления по целям» (целевое управление), предполагающая организацию управляющего воздействия на управляемый объект (одним из этих объектов были трудо- вые ресурсы) с целью достижения определенных результатов. Однако эта идея, получившая название программно-целевой, так и не нашла «выхода в практику», хотя и получила добротное теоретическое обоснование. В начале 90-х годов было ликвидировано Министерство электронной промышленности СССР, а вслед за ним ОГАС и сама электронная промышленность, занимавшая тогда второе место в мире по объему производства. Приостановилось развитие в Зеленограде мирового Центра электроники. Проектирование и создание суперкомпьютерной техники, а также отечественный рынок бытовой и промышленной электроники захватили зарубежные фирмы, что в конечном итоге привело к господству зарубежных аналитических и консалтинговых компаний на рынке аналитики и стратегически важных данных [2].

Думается, что с учетом современных достижений в области цифросферы (когнитивных технологий, облачных технологий, Big Data, промышленного Интернета и др.), процесс управления трудовыми ресурсами должен получить развернутую и более детальную цифровую интерпретацию. Традиционный механизм принятия управленческих решений следует заменить разветвленной и структурированной функцией, в рамках которой команда высококвалифицированных менеджеров может работать в постоянном взаимодействии с профессиональными аналитиками и консультантами, обеспечиваю- 
щими независимый экспертный взгляд на возникающие проблемы и объективный анализ вариантов их решений.

Непрерывные и всё ускоряющиеся преобразования в области цифровых технологий создают возможности для мониторинга изменений в характере и содержании труда, адекватной подстройки профессионально-квалификационных характеристик и компетенций работников, осуществления корректировки политики государства в области трудовых отношений. До недавнего времени основными чертами этой политики были: отказ от наращивания расходов на мероприятия непосредственно на рынке труда; приоритет институциональных изменений в сфере занятости, включая ужесточение системы страхования по безработице и либерализацию трудового законодательства; усиление экономической мотивации предпринимателей по найму наиболее уязвимых категорий рабочей силы; активизация, с одной стороны, работы самих служб занятости, а с другой - усилий безработных по поиску нового рабочего места; значительная либерализация понятия подходящей работы; увязка активности поисков работы с размером пособия, материальное поощрение безработных, которое трудно устраиваются в короткие сроки; упрощение процедур найма и увольнения [3].

Представляется, что цифровые технологии дают возможность ставить и решать такие амбициозные задачи в управлении трудовыми ресурсами, как:

- стратегическое планирование обеспечения реального сектора экономики рабочей силой необходимого количества и качества;

- пространственно-экономическое развитие российских регионов, включая рациональное распределение и перераспределение трудовых ресурсов по территории страны, отраслям экономики и сферам приложения труда (речь идет о преодолении сверхурбанистических процессов, поощряемых в России, вопреки необходимости рационального размещения населения на территории страны);

- экологизация сознания и техносферы, с подчинением последней духовным потребностям человека и отказом от бездумного потребительства, превращающего людей в рабов вещей;

- заметное сокращение теневого сектора экономики (исследование РАНХиГС установило, что в той или иной форме к теневой экономике причастно 32,5\% занятого населения, т.е. 25 млн. человек, а по данным Росстата скрытый фонд оплаты их труда в 2018 году составил более 13 трлн. рублей - 12,6\%) [4];

- разработка программы по возвращению в Россию высококвалифицированных специалистов и молодых ученых, работающих в зарубежных фирмах (по данным зарубежных источников их $-1,5$ млн. человек и согласно опросам 8 из 10 готовы при определенных условиях вернуться в Россию);

- ввести в управленческую практику понятие «рациональная занятость», содержанием которого должен стать расчет допустимого уровня безработицы в России и субъектах Федерации (по Кейнсу, например, это было 1,8\% от числа трудоспособного населения, в современной России этот показатель по официальным данным держится последние 10 лет на уровне 5-7\%) [5];

- использование на российских предприятиях различных форм собственности успешных решений (практик) повышения производительности труда и их тиражирование;

- создание «Целевой комплексной программы (ЦКП) «Трудовые ресурсы как цифровая платформа» (концепция программы предлагается автором).

Следует подчеркнуть, что эффективность управления трудовыми ресурсами определяется не только решением выше указанных задач. В первую очередь, количество и качество ресурсов труда зависит от демографической политики государства и от уровня человеческого развития, обобщающим показателем которого ООН с 1990 года использует - индекс развития человеческого потенциала (ИРЧП). Этот показатель отражает достижения каждой страны в обеспечении трех важнейших аспектов человеческого благополучия:

- здоровья, долголетия, измеряемых ожидаемой продолжительностью жизни;

- образования, измеряемого комбинацией двух индикаторов - грамотности взрослого населения и охвата его тремя ступенями образования (начальным, средним, высшим);

- материального уровня жизни, измеряемого величиной реального ВВП, переведенного в доллары с помощью ППС.

Анализ достоинств и недостатков ИРЧП не является предметом данной статьи, поэтому отметим, тем не менее, что среднемировое значение ИРЧП - 0,764; в развитых странах он со- 
ставляет 0,911, во всех развивающихся странах 0,576, в бедных и беднейших странах - 0,366, в России - 0,881, а это означает, что в классификаторе стран мира по рейтингу ИРЧП РФ находится на 49 месте [6].

В контексте рассматриваемой проблемы выделенные выше задачи в области управления трудовыми ресурсами носят агрегированный характер. Они могут быть описаны алгоритмически и, что очень важно, их решение обеспечивает общественное расширенное воспроизводство в его триединстве: воспроизводства совокупного общественного продукта (ВСОП), воспроизводства совокупной рабочей силы (ВСРС) и воспроизводства (развития) экономических отношений (ВЭО) (См. Приложение 3 «Количественная и качественная характеристика трудовых ресурсов России в сопоставлении с другими странами. Актуальная оценка.»).

Понятно, что управление интенсивной формой расширенного общественного воспроизводства с помощью новых средств информатики и вычислительной техники уже в наше время, т.е. на модернизационной фазе научнокибернетического цикла развития требует преобразования технологий управления в общее свойство научно-технологических достижений, прямо связанных с цифросферой, в которую, в первую очередь, следует отнести: когнитивные и облачные технологии, промышленный Интернет и Big Data.

Так, когнитивные технологии (когнитивные вычисления) можно использовать для обработки неструктурированной текстовой информации, что позволит существенно снизить трудозатраты на рутинные виды управленческой деятельности и автоматизировать основной документооборот, а также обрабатывать материалы (источники информации), собранные в Интернете. Эти технологии создают возможность производителю напрямую взаимодействовать с партнером, а потребителю легко находить производителя. В результате возникает возможность создания бизнес-модели С2М, М2С (manufacturing-to-customer, производительпотребитель) с обратной связью и тем самым избавляться от посредников в обмене деятельностью или ее результатами. Больше того, когнитивные технологии могут быть имплементированы в планирование и управление производством с помощью решений SAP ERP [7].

В свою очередь, информационно-техноло- гические системы, получившие название облачные технологии (вычисления), как системы повсеместного и облегченного сетевого доступа к общему объему конфигурируемых вычислительных ресурсов (это сети передачи данных, серверы, устройства хранения данных, приложения и сервисы, позволяют обрабатывать данные по запросу (on-demand) в качестве онлайнсервиса. Уже сейчас развитие этих технологий создает возможность осуществлять производство по требованию (production-on-demand), т.е. как услуги (production-as-a-service), что в дальнейшем приведет к кардинальному изменению содержания обмена как такового. Он сможет осуществляться без классического посредника в обращении - денег.

Технологии, называемые Интернетом вещей (IoT, Internet of things) и промышленным Интернетом вещей, предполагают сбор всевозможных данных, используемых для построения моделей и прогнозов создания потребительских благ, либо для автоматизации производства посредством дистанционного управления ресурсами (в том числе трудовыми) с помощью датчиков. Число таких систем растет стремительно. Если в 2019 году их было 530 млн. единиц, то, по прогнозам, в 2025 году их количество, возрастет до 20 млрд. единиц.

Наконец, Большие данные (Big Data), к которым относится совокупность подходов, инструментов и методов, используемых для обработки структурированных и неструктурированных источников информации в целях получения воспринимаемых человеком результатов, могут использоваться для принятия на этой основе эффективных решений. Примерами таких источников информации являются: логи поведения пользователей в Интернете; GPS сигналы от автомобилей для транспортных компаний; информация о транзакциях всех клиентов банков; информация о всех покупках в розничной сети; информация, получаемая с городских IP-видеокамер; информация с датчиков предприятий, использующих технологии промышленного Интернета и т.д.

Как видим, даже краткая характеристика некоторых, наиболее распространенных технологий, свидетельствует, что в них воплощаются современные достижения, отражающие новый уровень развития информатики и вычислительной техники и они могут быть использованы в качестве управленческой системы, насыщенной 
интеллектуальными и иными новациями, способной прогнозировать (планировать действия), рассчитанные на длительную перспективу и достижение стратегической цели с заданными индикаторами.

Возникающая под воздействием НТП (в его цифровом воплощении) новая экономика порождает и новые требования к управлению. Попытка прореагировать на это обстоятельство со стороны Российского государства вылилась в принятие Федерального закона от 28 июня 2014 г. № 172 «О стратегическом планировании в Российской Федерации» [8]. И хотя по мнению специалистов, этот закон пока еще не имеет «механизма действия» и, следовательно, он существует, но не действует, сам факт его принятия свидетельствует о том, что система управления общественным воспроизводством в форме закона получила в конце концов свое центральное звено регулирования отношений, возникающих между участниками стратегического планирования в процессе целеполагания, прогнозирования, планирования и программирования социально-экономического развития Российской Федерации, субъектов Российской Федерации и муниципальных образований, отраслей экономики и сфер государственного и муниципального управления, обеспечения национальной безопасности Российской Федерации, а также мониторинга и контроля реализации документов стратегического планирования (См. статью 3 указанного Федерального закона).

Однако высказанное нами суждение вовсе не означает, что планово-управленческое воздействие на экономические процессы при всей их «оцифрованности» может осуществляться в автоматическом режиме. Даже фаза саморегулируемых автономных систем, которая, по мнению Л.Е.Гринина и А.Л.Гринина, захватит период 2030-2070 годов, и будет отличаться тем, что системы смогут регулировать свою деятельность самостоятельно, отвечая, с помощью соответствующих программ, интеллектуальных и иных компонентов, на изменение окружающей среды, будут действовать при минимальном, но все же вмешательстве человека [9]. То есть известное высказывание К. Маркса о том, что «отдельный скрипач сам играет на скрипке, а оркестр нуждается в дирижере», думается, сохранит свою актуальность еще на многие тысячелетия, коль скоро таким дирижером давно перестала быть «невидимая рука рынка» А. Смита.

Как подчеркивает К.А.Смирнов, «примечательным является то, что во всех системах автоматического регулирования, в т.ч. созданных природой, мы не встречаем прямого воздействия на регулируемую величину (ничто не подогревает наше тело при его охлаждении, никто не подталкивает нас снизу при угрозе падения и т.д.) - такие системы были бы очень неэффективными. Всюду используется взаимосвязь регулируемой величины (того самого основного показателя системы - критерия оптимальности ее работы) с так называемыми параметрами регулирования. Эти параметры и являются средством достижения иди поддержания требуемого значения регулируемой величины» [10].

Следовательно, дирижерские (управленческие) функции должен взять на себя, используя терминологию К.А.Смирнова, «согласующий орган регулирования». В терминах экономической кибернетики результатом деятельности такого регулятора должно стать сведение к минимуму отклонения $\Delta$ (дельта) при удовлетворении научно обоснованных и действительно выявленных потребностей людей при минимизации издержек производства (в т.ч. затрат на воспроизводство рабочей силы).

Понятно, что такой согласующий орган регулирования должен быть оснащен современными средствами информатики и вычислительной техники, обеспечивающими самонастройку экономической системы по критерию (отличительному признаку) удовлетворения научно обоснованных производственных и личных потребностей. По мнению К.А. Смирнова, с которым при внесении в него ряда коррективов, трудно не согласиться, такой согласующий орган регулирования целесообразно составить из трех блоков: А. Блок изучения конечных потребностей (производственных и личных) и спроса предприятий и населения; Б. Блок мониторинга и оценки степени удовлетворения производственных и личных потребностей; В.Блок формирования рациональных (научно обоснованных) потребностей и спроса.

В управлении трудовыми ресурсами и трудом, как свидетельствует наш анализ, наиболее эффективной практикой является проектирование с помощью человеко-машинных систем. Значительную часть таких систем представляют алгоритмы оптимальной деятельности, реализуемой в пространстве и во времени. И в 
тех случаях, когда деятельность выступает не главной, а вспомогательной составляющей, все равно приходится решать комплекс задач так называемого операционно-деятельного проектирования (выделение операций, установление их порядка, формирование алгоритма, его оптимизация и проч.).

Еще одним методом, не менее важным, но пока еще недостаточно распространенным является временное проектирование. Его применение предполагает размещение процессов управления трудовыми ресурсами в социальном времени, что позволяет учитывать вектор времени одновременно с развитием, синхронностью, ритмичностью этих процессов. К этому относится и пространственное проектирование, учитывающее размещение трудовых ресурсов в пространстве трудовой деятельности, а также в пространстве свободного времени людей как той части их нерабочего времени, в которой они могут развиваться физически, интеллектуально и духовно.

Наконец, в управлении трудовыми ресурсами можно использовать структурно-функциональное проектирование, осуществляемое путем формирования требований к технологиям отображения действительности. «На входе» проекта определяются функции технологии, а «на выходе» - конечный результат. С кибернетической точки зрения такой подход считается «признаком черного ящика». В этом случае смысл проектирования заключается в том, чтобы «черный ящик» (в данном случае модель технологии проектирования) модифицировать в «светлый» посредством раскрытия структуры проектирования.

Нельзя не отметить, что применение цифровых технологий предполагает постоянное взаимодействие органов управления с организациями, деятельность которых связана с информационно-компьютерными технологиями (ИКТ) и оказанием услуг в этой сфере, результатами которой являются: во-первых, товары, удовлетворяющие одно из перечисленных ниже требований: предназначены для обеспечения работы телекоммуникационной связи и выполнения функций обработки информации, включая ее передачу и отображение; используют электронику для обнаружения, изменения и/или описания физических явлений и управления физическими процессами; являются отдельными компонентами, предназначенными преимущественно для использования в товарах, определенных выше.

Что касается услуг, то они призваны обеспечить возможности для обработки и передачи информации с помощью электронных средств, в т.ч. связанных с непосредственным применением ИКТ в управлении (см. Международный статистический стандарт).

При этом следует учитывать, что технологизация управления трудовыми ресурсами должна осуществляться поэтапно:

- на теоретическом этапе определяются цели, конкретизируются объекты технологизации, их структура и взаимосвязи внутри этой структуры;

- на методическом этапе определяются методы, средства получения информации и способы ее обработки, а также, трансформируемые в конкретные выводы и рекомендации;

- на процедурном этапе организуется практическая деятельность по управлению трудовыми ресурсами и определяется его эффективность, т.е. соизмеряются результаты управления с заданными целями, затраченными усилиями и ресурсами.

В заключении отметим, что управление трудовыми ресурсами невозможно без наличия профессиональных, стратегически мыслящих и инновационно-ориентированных специалистов на всех уровнях: от квалифицированных рабочих, инженеров, конструкторов, ученых, предпринимателей, до управленцев и государственных руководящих кадров. Наш анализ количественных и качественных характеристик современных трудовых ресурсов побуждает к выводу о необходимости серьезного совершенствования всей образовательной системы РФ, ее синтезирования с революцией в области информатики и вычислительной техники, обеспечивающего повышения фундаментальности, креативности и непрерывности образования. Для этого требуется:

- повысить фундаментальность школьного и вузовского образования, наполнить его достижениями современных ИКТ, ориентируясь на опережающую подготовку функциональных кадров; наладить более тесные связи (в т.ч. интерактивные) между хозяйствующими субъектами различных форм собственности и учреждениями образования;

- создать условия для непрерывности образования, переподготовки и повышения квали- 
фикации экономически-активного населения на всех этапах его юридической трудоспособности (14-65 лет), поскольку за этот период происходит смена 5-6 поколений техники и технологий;

- детализировать баланс трудовых ресурсов России применительно к условиям, возникшим в результате изменения пенсионного возраста. Этот важнейший показатель отражает численность трудовых ресурсов и их качественный состав, позволяет определить потребность в работниках той или иной квалификации и компетенции или их избыток.

Такой баланс как имманентная часть баланса народного хозяйства, составляется с учетом пополнения и выбытия работников, сферы их занятости, производительности труда и состоит из двух частей: в первой фиксируется численность и состав трудовых ресурсов, а во второй их распределение. Последнее производится по видам занятости, по сферам приложения труда (материальное и нематериальное производство), кластерам, отраслям экономики, социальным группам. Представляется очень важным, а для России сверхважным, осуществление политики рационального размещения населения, a, следовательно, и трудовых ресурсов и других производительных сил по территории страны, поскольку решение этой задачи обеспечивает живучесть нашей экономики в сверхмажорных ситуациях.

\section{Библиографический список}

1. Будущее экономики России. Роль цифросферы. Монография. -М.: ММА, 2018.- С.115.

2. Там же.- C.117.

3. Мировая экономика: глобальные тенденции за 100 лет. Под. ред. И. С. Королева.- М.: Юристъ, 2003 -С.151154.

4. https://social.ranepa.ru/tsentry-i-instituty/tsentr-sotsialno-politicheskogo-monitoringa/issledovaniya/ 25-stimuly-i-motivy-uchastiya-rabotnikov-zanyatykh-po-najmu-v-ofitsialnoj-i-nekriminalnoj-tenevojekonomicheskoj-deyatelnosti

5. https://rosstat.gov.ru/labour_force

6. https://social.ranepa.ru/tsentry-i-instituty/tsentr-sotsialno-politicheskogo-monitoringa/issledovaniya/ 25-stimuly-i-motivy-uchastiya-rabotnikov-zanyatykh-po-najmu-v-ofitsialnoj-i-nekriminalnoj-tenevojekonomicheskoj-deyatelnosti

7. Планирование и управление производством с помощью решений SAP ERP. Йорг Томас Дикерсбах, Герхард Келлер. Перевод с англ. -Спб.: Эксперт, 2011.-608 с.

8. «О стратегическом планировании в РФ», ФЗ № 172 от 28.06.2014 г.

9. Гринин Л.Е., Гринин А.Л. Кибернетическая революция и шестой технологический уклад. // Историческая психология и социальная история, 2015. № 1. -С.187.

10. История русской экономической мысли в XX веке. Под науч. ред. проф.д.э.н. К.А. Смирнова. Монография. -М.: ИНФРА-М, 2013. -С.241 